(2) Open Access Full Text Article

ORIGINAL RESEARCH

\title{
Association Between Everyday Technology Use, Activities of Daily Living and Health-Related Quality of Life in Chronic Obstructive Pulmonary Disease
}

Rina Juel Kaptain (1D ${ }^{1,2}$

Tina Helle ${ }^{1,2}$

Ann-Helen Patomella (D) ${ }^{2}$ Ulla Møller Weinreich (1D)

Anders Kottorp $\mathbb{1 D}^{2,5}$

'Department of Occupational Therapy, University College of Northern

Denmark, Aalborg, Denmark;

${ }^{2}$ Department of Neurobiology, Care

Sciences and Society, Division of

Occupational Therapy, Karolinska

Institutet, Stockholm, Sweden;

${ }^{3}$ Department of Respiratory Diseases,

Aalborg University Hospital, Aalborg,

Denmark; ${ }^{4}$ The Clinical Institute, Aalborg

University, Aalborg, Denmark; ${ }^{5}$ Faculty of

Health and Society, Malmö University,

Malmö, Sweden

This article was published in the following Dove Press journal:

International Journal of Chronic Obstructive Pulmonary Disease

\begin{abstract}
Purpose: A decline in the ability to perform activities of daily living (ADL) and ability to use everyday technology can pose threats to independent living, healthcare management and quality of life (QOL) of patients suffering from chronic obstructive pulmonary disease (COPD). Evidence of the relationship between these variables remains limited. The dual aim of this study was, first, to investigate if health-related QOL (HRQOL) was associated with quality in ADL performance and everyday technology use; second, to examine whether lung function, years with COPD diagnosis, living status or educational level affected physical and mental domains of HRQOL.
\end{abstract}

Methods: This cross-sectional study included $(\mathrm{N}=80)$ participants aged 46-87 years recruited at healthcare centres in the Northern Region of Denmark using a convenience sampling procedure. Data were gathered through standardized assessments and analysed using multiple regression analysis.

Results: The regression model explained $50.6 \%\left(\mathrm{R}^{2}=0.506\right)$ of the variation in HRQOLphysical. The following four variables were statistically significantly associated with HRQOL - physical: years since COPD diagnosis $(p=0.023)$, ability to use everyday technology $(p=0.006)$, amount of relevant everyday technologies $(p=0.015)$ and ADL motor ability $(p<0.01)$. The regression model explained $22.80 \%\left(\mathrm{R}^{2}=0.228\right)$ of HRQOL - mental. Only the variable ability to use everyday technology was statistically significantly associated with HRQOL - mental $(p=0.009)$.

Conclusion: Quality of ADL performance and everyday technology use seem to be associated with HRQOL in people living with COPD. The only demographic variable associated with HRQOL was years with COPD. This indicates that healthcare professionals should enhance their attention also to ADL-performance and everyday technology use when striving to increase the HRQOL of persons living with COPD.

Keywords: ADL, AMPS, ETUQ, occupational therapy, SF36

\section{Introduction}

Health-related quality of life (HRQOL) has been defined as an individual's perception of physical and mental health ${ }^{1}$ and is considered one of the primary end-points in pulmonary rehabilitation. ${ }^{2,3}$ In chronic obstructive pulmonary disease (COPD), a decrease in HRQOL may be caused several general and disease-related factors including a decrease in the ability to perform activities of daily living (ADL) $)^{3-9}$ and
Correspondence: Rina Juel Kaptain Selma Lagerloefs Vej 2, Aalborg 9220 Denmark

Tel +4572690928

Email rio@ucn.dk 
use of everyday technology, which has become an important part of performing ADL.

ADL refers to tasks the individual finds relevant to perform to cover basic needs such as eating, staying clean and being appropriately dressed as well as more complex tasks relevant for independent living such as transportation, cooking, shopping, cleaning and washing. ${ }^{10-12}$ HRQOL reduction in ADL is often multifactorial in COPD. $\mathrm{Hu}$ and $\mathrm{Meek}^{13}$ emphasize that a reduced ADL ability is closely related to breathlessness, which has a significant impact on HRQOL. Other frequently encountered symptoms are fatigue ${ }^{14}$ and anxiety, ${ }^{15}$ which affect social activities and the performance of ADL both inside and outside the home. ${ }^{13,16-20}$ Three studies have investigated breathlessness in the context of ADL and found that intervention may be instrumental in improving functioning, well-being or even prognosis. ${ }^{21-23}$ Spruit et $\mathrm{al}^{2}$ stated that two of the goals in pulmonary rehabilitation are to increase participation in everyday activities and enhance HRQOL. This supports other studies finding that more knowledge of the relation between ADL and HRQOL is important. ${ }^{4,7}$

The use of everyday technology has also become increasingly important to the performance of ADL as our physical environment comprises a growing number of technological artefacts and services. ${ }^{24}$ Everyday technologies include electronic, technical and mechanical equipment that people utilize in their daily lives, eg, microwaves, smartphones or scanners at the supermarket, or digital services like home-banking, e-post and ordering of grocery. ${ }^{25-27}$ Besides, everyday technologies such as social media, video calls or e-mails have become essential ways of participating in social life. The use of everyday technology to maintain social contact is particularly crucial to people with COPD who may find themselves restrained from participation in social life if weather conditions threaten to worsen their symptoms or if physical restrictions cause difficulties related to transportation. ${ }^{4,28}$ Finally, the ability to use everyday technology has also become increasingly important in order to manage personal health care, notably in light of the growing use of technology-based rehabilitation services such as telemedicine or e-health, which may involve video-conferences, online renewal of prescriptions, etc. ${ }^{29,30}$ Although everyday technologies offer helpful solutions, some people with COPD may encounter barriers in using these technologies due to reduced cognitive functions. ${ }^{31,32}$ Accordingly, a decline in the ability to perform ADL and use everyday technology can pose threats to independent living, healthcare management and HRQOL. However, evidence of the relationship between HRQOL and a decline in the ability to perform ADL and use technology remains limited.

ADL has been investigated in relation to objective variables such as age, lung function and living status with findings of only weak associations. ${ }^{4,7}$ Further, varying results have been found when investigating relations between HRQOL and objective variables. ${ }^{33,34}$ However, it is useful to gain knowledge of which variables influence the HRQOL and we hypothesized that both ADL performance and everyday technology use were associated with HRQOL and further variables as lung function, years with COPD, living status and educational level.

Therefore, the primary aim of this study was to investigate if HRQOL was associated with quality in ADL performance and everyday technology use. Moreover, a secondary aim was to examine whether lung function, years with COPD, living status or educational level affected HRQOL.

\section{Materials and Methods Design and Sample}

This was a cross-sectional study involving $(\mathrm{N}=80)$ participants aged $46-87$ years, who were recruited at healthcare centres in the Northern Region of Denmark. Participants were recruited using a convenience sampling procedure ${ }^{35}$ until the target sample $(\mathrm{N}=100)$ was reached. Participants were eligible for inclusion when registered with a COPD diagnosis in the primary healthcare and when all evaluations within this study were gathered. Participants were excluded from participation if they were unable to understand Danish sufficiently to answer the questionnaires in Danish or if they were living in nursing homes, had a diagnosed cognitive impairment or a visual or hearing impairment that could not be compensated for by technical aids. Nurses at the healthcare centres were informed about the inclusion and exclusion criteria that they used asking potential participants if they were willing to be contacted by telephone. The criteria were verified by the first (RJK) or second (TIH) author when contacting the participants. The number of exclusions was not registered.

\section{Instrumentation}

\section{Health-Related Quality of Life}

The Medical Outcomes Study Short Form 36 (SF36) is a well-established generic HRQOL instrument that has 
been validated in populations with $\mathrm{COPD}^{8,36}$ in Danish. ${ }^{37}$ SF36 is a self-reported questionnaire that consists of eight subscales: physical functioning, role-physical, bodily pain, general health, vitality, social functioning, role-emotional and mental health. The final measures are expressed in two summery scores indicating the physical and the mental health-related QOL. ${ }^{13,37}$

SF36 questionnaires were handed out to the participants at the first home visit and each participant completed the scorings before the second home visit.

\section{ADL-Performance}

Assessment of Motor and Process Skills (AMPS) ${ }^{11}$ is a standardized observation-based assessment tool for measuring the quality of a person's ADL task performance. The AMPS is an internationally recognized valid and reliable tool that has been used in persons with and without a diagnosis, including a diagnosis of COPD, and across ages and genders. ${ }^{11}$ The AMPS can be used by occupational therapists who have completed a training course and are calibrated as raters. Tasks often selected in this study are eg, vacuuming, putting away clean dishes from a dishwasher or making a pot of coffee or tea.

When performing an AMPS, the person being evaluated chooses and performs at least two standardized ADL tasks that the person is familiar with and finds appropriate in the level of challenge. The occupational therapist evaluates the quality of the ADL performance by scoring 16 motor skills and 20 process skills according to physical effort, efficiency, safety and independence on a 4-point criterion-referenced scale, ranging from competent (4) to unacceptable (1). The AMPS software is based on a Rasch measurement model that is then used to convert the ordinal raw scores from the two tasks observed into overall linear measures of ADL motor ability and ADL process ability, adjusted to task challenge, skill item difficulty and rater severity. ${ }^{11}$

\section{Everyday Technology Use and Relevance}

The participants were interviewed using the Everyday Technology Use Questionnaire (ETUQ) ${ }^{38}$ for evaluation of their perceived ability to use everyday technology and the individual amount of relevant everyday technologies at home and in public places. ${ }^{36}$ The psychometric properties of the ETUQ have earlier demonstrated evidence of validity and precision/reliability. ${ }^{39-42}$ The ETUQ utilized in this study has been translated into Danish and consists of 93 items. It has demonstrated excellent test-retest and inter- rater reliability in older adults with and without chronic diseases, including COPD. ${ }^{39}$

The ETUQ is administered as a structured face-to-face interview where the interviewer initially explores whether everyday technology is relevant for the person's current life situation. If so, the interviewer explores the extent to which the person may perceive difficulties in using the everyday technology in question. Ratings are marked according to an ordinal five-category rating scale, ranging from no perceived difficulties (5) to not using the technology anymore (1). ${ }^{42}$

\section{Procedures}

In preparation for data collection, five occupational therapists were trained for 2 days in using the ETUQ by the developers of the instrument. Moreover, they were instructed in using the Vitalograph copd-6 (Vitalograph Ltd, Buckingham, United Kingdom) according to the American Thoracic Society and European Respiratory Society standardization of spirometry ${ }^{43}$ by an expert from Aalborg University. Data were collected at two home visits performed with 1- to 3 -week interval from April 2016 to January 2017. The first home visit was performed by one of the five occupational therapists; the second by 1 of 10 occupational therapy students trained in performing the AMPS and thoroughly introduced to data collecting procedures. At the first home visit, participants were first orally informed about the study aim and also provided with an information letter before the written consent was obtained. Second, the Vitalograph copd-6 was used to gather a simple, up-to-date measurement of lung function (forced expiratory volume (FEV) $1 \%$ predicted). As the spirometry was intended for evaluating disease severity only, no reversibility test was done. ${ }^{43}$ Then, information regarding sample characteristics was collected following a structured plan, and the ETUQ was administered. Based on the overall information, it was decided, together with the participant, which two AMPS tasks the participant were to perform at the second home visit. At the end of the first home visit, the participant was introduced to how to complete the SF36, which was handed out. Within 1 to 3 weeks, the second home visit was conducted by an occupational therapy student who then performed the AMPS evaluation and gathered the completed SF36 scorings.

\section{Data Analysis}

The raw scores from the AMPS and the ETUQ were initially transformed from ordinal into interval measures (expressed in logits) based on Rasch rating scale models. ${ }^{44}$ These procedures have been described more in detail elsewhere. $^{41,45-47}$ The measures of HRQOL were 
calculated using SF-36 statistical software. Descriptive analyses to summarize data were presented as mean, standard deviations (SD) and minimum/maximum scores for continuous variables, whereas categorical variables were expressed as number of cases and percentages (\%).

To investigate which variables were associated with HRQOL, multivariable linear regression analyses were performed. ${ }^{48}$ Initially, an investigation if the data met the underlying assumptions (linearity, normality, multicollinearity, homoscedasticity) for a regression analysis was performed. ${ }^{48}$ As all assumptions were met, we continued with the regression analysis. The hierarchical (block-wise entry) regression model was used in three steps. ${ }^{48}$ The independent variables entered at the first two steps were based on theoretical knowledge selected on the basis of former studies of COPD, ${ }^{4,33}$ whereas the third step added the variables not earlier investigated accordingly. First, the level of education and living conditions were entered into the model. Second, lung function (FEV1\% predicted) and years since COPD diagnosis were entered. Third, the amount of relevant everyday technologies and the Rasch score reflecting the ability to use everyday technology, ADL motor ability and ADL process ability were entered into the model. In addition, an interaction variable between ADL motor ability and ADL process ability was calculated and entered, ${ }^{48}$ as a relationship exists between these aspects of ADL performance. ${ }^{11}$ Since HRQOL has both a physical and a mental summary score, multivariable linear regression analyses were performed with each score as the dependent variable. P-values $<0.05$ were considered statistically significant.

The variance inflation factor (VIF) is a collinearity measure that was used to indicate whether any included independent variable had a strong linear relationship with another variable. ${ }^{48}$ VIF was interpreted according to the following guidelines: a) $1=$ not correlated, b) between 1 and $5=$ moderately correlated, c) greater than $5=$ highly correlated. ${ }^{49}$ Statistical analyses were performed using the Statistical Package for the Social Sciences (SPSS) Statistics Version 25 (IBM Corp., New York, United States).

\section{Results}

Of the 100 participants recruited, 80 were included in the final analyses. The exclusions were caused by incomplete SF-36 questionnaires or AMPS evaluations. Characteristics of the participants included in the final analyses are shown in
Table 1. Measures of HRQOL, ADL motor ability, ADL process ability and everyday technology use are presented in Table 2.

\section{Variables Associated with Health-Related Quality of Life-Physical}

The following four variables were statistically significantly associated with HRQOL - physical: years since COPD diagnosis $(p=0.023)$, ability to use everyday technology $(p=0.006)$, amount of relevant everyday technologies $(p=0.015)$ and ADL motor ability $(p<0.01)$. In this model, the interaction variable between ADL motor ability and ADL process ability was close but not statistically significant $(p=0.051)$. The regression model (step 3) explained $50.6 \%$ $\left(\mathrm{R}^{2}=0.506\right)$ of the variation in HRQOL-physical. Step $1\left(\mathrm{R}^{2}=0.003\right)$ and step $2\left(\mathrm{R}^{2}=0.230\right)$ indicating step 3 to be essential. VIF (1.087-1.935) showed no indication of concern (Table 3 ).

Table I Characteristics of the Study Participants $(\mathrm{N}=80)$

\begin{tabular}{|l|l|l|l|}
\hline & N (\%) & Mean \pm SD & $\begin{array}{l}\text { Minimum/ } \\
\text { Maximum }\end{array}$ \\
\hline Age at date of interview & $80(100)$ & $70.05 \pm 9.38$ & $46 / 87$ \\
\hline Male & $30(38)$ & & \\
Female & $50(62)$ & & \\
\hline Classification of COPD $:$ & $78(98)$ & & \\
Normal & $4(5)$ & & \\
Stage I & $17(21)$ & & \\
Stage II & $50(62)$ & & \\
Stage III & $7(9)$ & & \\
Stage IV & 0 & & \\
\hline Years with COPD & $79(99)$ & $10.32 \pm 7.13$ & $1 / 41$ \\
\hline Education: & $77(96)$ & & \\
Primary school/skilled worker & $60(75)$ & & \\
Student/higher education & $17(21)$ & & \\
\hline Living conditions: & $80(100)$ & & \\
Living alone & $37(46)$ & & \\
Cohabiting & $43(54)$ & & \\
\hline Comorbidities: & $80(100)$ & & \\
Diabetes & $2(2.5)$ & & \\
Cardiovascular disease & $9(11)$ & & \\
Mental illness & $5(6)$ & & \\
Illness in muscles/bones/joints & $24(30)$ & & \\
Cancer & $2(2.5)$ & & \\
None & $38(47)$ & & \\
\hline Notes: Based & & \\
\hline
\end{tabular}

Notes: ${ }^{\text {a }}$ ased on the measure definitions of lung function from Vitalograph COPD-6. Abbreviation: COPD, chronic obstructive pulmonary disease. 
Table 2 Measures of Physical and Mental HRQOL, ADL Motor Ability and ADL Process Ability, Number of Relevant Everyday Technologies and Ability to Use Everyday Technology

\begin{tabular}{|l|l|l|l|l|}
\hline & N (\%) & Mean \pm SD & Minimum/Maximum & Cut-off \\
\hline HRQOL physical sum score $^{\mathrm{a}}$ & $80(100)$ & $37.45 \pm 9.17$ & $16.74 / 57.42$ & 50 \\
HRQOL mental sum score $^{\mathrm{a}}$ & $80(100)$ & $51.68 \pm 11.42$ & $17.16 / 72.01$ & 50 \\
ADL - motor ability (logits) $^{\mathrm{b}}$ & $80(100)$ & $1.18 \pm 0.59$ & $-0.4 / 2.6$ & 2.0 \\
ADL - process ability (logits) $^{\mathrm{b}}$ & $80(100)$ & $1.04 \pm 0.43$ & $0 / 2.2$ & 1.0 \\
ET relevance (ETUQ) (number of relevant everyday technologies) $^{c}$ & $80(100)$ & $45.46 \pm 11.82$ & $14 / 67$ & - \\
ET ability (ETUQ) (logits) $^{c}$ & $80(100)$ & $56.58 \pm 5.79$ & $46.86 / 80.02$ & - \\
\hline
\end{tabular}

Notes: a'Measured by the Medical Outcomes Study Short Form 36 (SF36), ${ }^{b}$ Measured by the Assessment of motor and process skills (AMPS), ${ }^{c}$ Measured by Everyday technology use questionnaire (ETUQ).

Abbreviations: HRQOL, health-related quality of life; ADL, activities of daily living; ET, everyday technology; ETUQ, everyday technology use questionnaire.

\section{Variables Associated with Health-Related Quality of Life-Mental}

Only the variable ability to use everyday technology was statistically significantly associated with HRQOL - mental $(p=0.009)$. The regression model (step 3) explained $22.80 \%\left(\mathrm{R}^{2}=0.228\right)$ of HRQOL mental. Step $1\left(\mathrm{R}^{2}=0.018\right)$ and step $2\left(\mathrm{R}^{2}=0.085\right)$. VIF (1.087-1.935) showed no indication of concern between the independent variables (Table 4).

\section{Discussion}

This study shows that both everyday technology use and quality in ADL performance were associated with HRQOL in people with COPD. To the authors' knowledge, the finding that the ability to use everyday technology was associated with QOL has not previously been reported. Further, the study shows that of the variables connected to the second aim, only years with COPD diagnosis was associated with QOL. Together, this is important new knowledge in relation

Table 3 Multivariable Linear Regression Analyses for Health-Related Quality of Life-Physical

\begin{tabular}{|c|c|c|c|c|c|c|}
\hline & $\mathbf{R}^{2}$ & B & SE B & $\beta$ & $\mathbf{p}$ & VIF \\
\hline & 0.003 & & & & & \\
\hline Educational level & & 1.154 & 2.684 & 0.053 & 0.669 & 1.013 \\
\hline \multirow[t]{2}{*}{ Living status } & & 0.484 & 2.326 & 0.026 & 0.836 & 1.013 \\
\hline & 0.023 & & & & & \\
\hline Educational level & & 1.095 & 2.642 & 0.050 & 0.680 & 1.032 \\
\hline Living status & & 0.795 & 2.273 & 0.042 & 0.728 & 1.017 \\
\hline FEVI\%predicted & & 0.100 & 0.161 & 0.161 & 0.187 & 1.026 \\
\hline \multirow[t]{2}{*}{ Years with COPD } & & -0.335 & -0.242 & -0.242 & 0.048 & 1.016 \\
\hline & 0.506 & & & & & \\
\hline Educational level & & -1.037 & 2.051 & -0.047 & 0.615 & 1.087 \\
\hline Living status & & -2.138 & 1.802 & -0.113 & 0.240 & 1.118 \\
\hline FEVI\%predicted & & 0.003 & 0.059 & 0.005 & 0.959 & 1.119 \\
\hline Years with COPD & & -0.308 & 0.132 & -0.223 & 0.023 & 1.129 \\
\hline ET ability ${ }^{\mathrm{a}}$ & & 0.456 & 0.160 & 0.284 & 0.006 & 1.229 \\
\hline ET relevance ${ }^{a}$ & & 0.194 & 0.077 & 0.242 & 0.015 & 1.144 \\
\hline ADL Motor ${ }^{\mathrm{b}}$ ability & & 8.155 & 2.046 & 0.499 & 0.000 & 1.935 \\
\hline ADL Process ability ${ }^{b}$ & & -1.905 & 2.750 & -0.084 & 0.491 & 1.815 \\
\hline Interaction variable ( $A D L$ motor/process ability) & & -5.677 & 2.848 & -1.253 & 0.051 & - \\
\hline
\end{tabular}

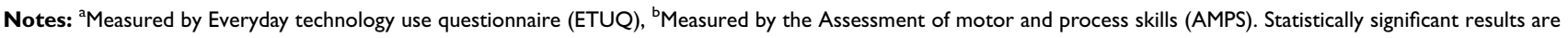
highlighted in bold.

Abbreviations: FEVI, forced expiratory volume; COPD, chronic obstructive pulmonary disease; ET, Everyday technology; ADL, activities of daily living. 
Table 4 Multivariable Linear Regression Analyses for Health-Related Quality of Life-Mental

\begin{tabular}{|c|c|c|c|c|c|c|}
\hline & $\mathbf{R}^{2}$ & B & SE B & $\beta$ & $\mathbf{p}$ & VIF \\
\hline & 0.018 & & & & & \\
\hline Educational level & & 3.368 & 3.044 & 0.135 & 0.273 & 1.013 \\
\hline \multirow[t]{2}{*}{ Living status } & & 0.181 & 2.638 & 0.008 & 0.945 & 1.013 \\
\hline & 0.085 & & & & & \\
\hline Educational level & & 2.512 & 3.009 & 0.101 & 0.969 & 1.032 \\
\hline Living status & & 0.154 & 2.589 & 0.007 & 0.983 & 1.017 \\
\hline \multirow[t]{3}{*}{ FECI\% predicted } & & 0.137 & 0.086 & 0.193 & 0.974 & 1.026 \\
\hline & & 0.251 & 0.189 & 0.159 & 0.984 & 1.016 \\
\hline & 0.228 & & & & & \\
\hline Educational level & & 1.679 & 2.931 & 0.067 & 0.569 & 1.087 \\
\hline Living status & & -1.748 & 2.575 & $-0.08 I$ & 0.500 & 1.118 \\
\hline FEVI\% predicted & & 0.086 & 0.085 & 0.120 & 0.317 & 1.119 \\
\hline Years with COPD & & 0.317 & 0.189 & 0.201 & 0.099 & 1.129 \\
\hline ET ability ${ }^{a}$ & & 0.622 & 0.229 & 0.339 & 0.009 & 1.229 \\
\hline ET relevance $^{\mathrm{a}}$ & & 0.052 & 0.110 & 0.057 & 0.636 & 1.144 \\
\hline ADL motor ability ${ }^{b}$ & & 0.904 & 2.923 & 0.048 & 0.758 & 1.935 \\
\hline ADL process ability ${ }^{b}$ & & 2.237 & 3.928 & 0.086 & 0.571 & 1.815 \\
\hline Interaction variable (motor/process skills) & & 2.555 & 4.189 & 0.493 & 0.544 & - \\
\hline
\end{tabular}

Notes: ${ }^{a}$ Measured by Everyday technology use questionnaire (ETUQ), ${ }^{b}$ Mesasured by the Assessment of motor and process skills (AMPS). Statistically significant results are highlighted in bold.

Abbreviations: FEVI, forced expiratory volume; COPD, chronic obstructive pulmonary disease; ET, everyday technology; ADL, activities of daily living.

to performing ADL, participating in social relations and using E-health. Firstly, health professionals supporting persons with COPD in managing their everyday life should be more aware that their clients may encounter challenges in relation to ordinary ADL like using internet banking, selfscanners at the supermarket or the vacuum cleaner at home. These difficulties may be detected using the ETUQ. Secondly, when social relations are limited because of physical restrictions, ${ }^{50}$ resort to use of social media may be a valuable means to maintain relations. However, if persons with COPD find it difficult to use social media or have no access to such media, introduction to these media or support from health professionals could help minimize isolation and ensuing depression as described by Hu \& Meek. ${ }^{13}$ Thirdly, recent years have seen an increase in the use of telemedicine and E-health both in Denmark and internationally. ${ }^{51,52}$ Based on the findings of everyday technology use in the present study, we argue that it is important for health professionals to be aware of how use of everyday technology may enhance HRQOL in people with COPD. It should be emphasized that difficulty in using technology is evidently a barrier, as well as poor accessibility and little perceived relevance of everyday technology in general, as indicated by Early ${ }^{53}$ in relation to motivation in use of more specific e-health technologies. It is therefore critical to examine to what extent people with COPD find it relevant and are able to use everyday technology to manage their health conditions in general and their everyday life in particular. Moreover, given that people living with COPD may experience a decrease in their ADL, this population may find it even more important to deploy a variety of everyday technologies to compensate for their functional limitations like breathlessness and fatigue.

The large variation in both ADL motor ability and ADL process ability (Table 2) indicates that the diagnosis of COPD affects not only motor aspects of ADL performance but also other quality aspects such as efficiency and safety in ADL performance. This is supported by Schou et a ${ }^{31}$ who found that people with COPD had reduced cognitive functions, eg, memory, attention or learning abilities, which may also affect process abilities. The decrease in process abilities is another aspect that must be recognized as support might be needed to handle a computer or to organize and initiate daily activities, for example. Schou et $\mathrm{a}^{31}$ also suggest that future studies should address the consequences of cognitive dysfunction for daily living. The findings of the present study show that people with COPD had lower physical HRQOL than mental HRQOL (Table 3). These results are 
supported by a study by Bentsen et $\mathrm{al}^{54}$ where participants with COPD demonstrated lower HRQOL than the general population, and also had lower scores on physical than mental HRQOL. However, in the present study sample, we found large variation from minimum to maximum score in both physical and mental HRQOL. This is of concern as it indicates that some people with COPD have a very low HRQOL. Reardon et $\mathrm{al}^{55}$ describe that disparate trajectories in the individual's health expectations, physical deconditioning and activity levels may also cause different trajectories of symptoms, functional status and HRQOL. Accordingly, several variables do impact on HRQOL, ${ }^{2,13}$ and with more knowledge of these variables, health professionals may become better at supporting these trajectories in positive directions.

This study indicates that lung function is not associated with HRQOL (Tables 3 and 4). This may suggest that healthcare professionals to a higher degree preferably should consider other variables when planning different kinds of interventions. The number of years with COPD is in this study associated with HRQOL which could be explained by people adapting to their deteriorating health through the years. ${ }^{56,57}$ Research has shown that when lungs are damaged beyond repair, participants assume that their situation cannot be improved, and they tend not asking for help. ${ }^{56}$ This leads another responsibility to the health professionals supporting people with COPD to draw attention to how they could improve their performance of ADL, their use of everyday technology or participation in social relations in order to increase HRQOL. This includes the presentation of and training in using new relevant everyday technologies to learn how to perform $\mathrm{ADL}$ in other ways. One example could be training people living with COPD in how to do an online grocery with service delivery to avoid windy weather, high humidity or other aspects influencing this ADL ability.

Several variables could be considered when discussing the use of everyday technology, eg, age, gender, education and income. ${ }^{58}$ Further, social determinants as disability status, relationship status and urban/rural residence are found to impact the use of technology as well as individualized usability of and accessibility to the technology. ${ }^{59}$ Enhancing participation in society and daily life through the use of everyday technology is important in maintaining independence and improving well-being and QOL. ${ }^{60,61}$ Further, co-morbidities have been recognized as affecting QOL. ${ }^{62,63}$ However, in this study the co-morbidities were registered (Table 1) but not integrated into the analyses as it was not a part of the aim.

A main strength of the present study is that the authors relied on assessments of psychometric properties that are well described and have been used in various samples (including but not limited to people with COPD) and in Danish contexts. In the SF36, the physical and mental summary scores are used separately in the analysis, as recommended by Lins and Carvalho, ${ }^{64}$ instead of as one overall score. Another strength of this study is the way in which the sample is distributed across several stages of COPD. Onefifth of the participants were stage I, two-thirds stage II, onetenth stage III and none were stage IV (Table 1), which only varies slightly from the stage-distribution in the Danish COPD population. ${ }^{65}$

The present study is limited by using a generic HRQOL assessment tool instead of a disease-specific one like St. George's Respiratory Questionnaire, which has shown to be more sensitive. ${ }^{3}$ However, studies do use both measurements and find them sensitive to several variables. ${ }^{66,67}$ Within the COPD literature, the SF36 has been used as a measure of HRQOL in eg, cross-sectional studies and as an outcome measure for evaluating interventions. ${ }^{3}$ Moreover, in the present study, the SF36 was selected because we wished to be able to compare our results with other studies performed in the Northern Denmark Region.

Another limitation is the fact that the sample size did not allow us to study the chosen outcomes in sample subgroups stratified by age, gender or lung function. On the other hand, when determining the sample size for this study, practical and ethical considerations were taken into account by seeking to avoid exhaustion with respect to duration and number of assessments undertaken at each home visit. We also decided to use $p<0.05$ as a cut-off value for statistical significance across all analyses. The impact of multiple testing could on the chosen significance level in addition to the relatively small sample suggest some caution in interpreting the impact of the results. The findings from the study should, therefore, be viewed more as indicative than conclusive.

In this study we performed spirometry on the participants, primarily to evaluate disease severity in the participants. A Vitalograph copd-6 (Vitalograph Ltd, Buckingham, United Kingdom) spirometer was used, measuring FEV1/FEV6 rather than FEV1/FVC, which was a limitation to this study. Although the FEV1/FEV6 ratio previously has been evaluated as a valid tool to screen for airway obstruction in primary care $^{68}$ sensitivity is only 0.75 . In this study four participants previously diagnosed with COPD and thereby an FEV1/FVC ratio $<0.7$ had a ratio above 0.7 . Four patients out of 30 are consistent with a sensitivity as mentioned above, and therefore patients were kept in the study. 
According to the Official American Thoracic Society/European Respiratory Society Statement: Key Concepts and Advances in Pulmonary Rehabilitation, ${ }^{2}$ it is important to further study the individualized measures of occupational and daily activity limitations. In the present study, ADL and everyday technology use have been defined and measured using methods that may add new knowledge to the COPD area. The ETUQ was used for evaluation of everyday technology and the AMPS for evaluation of performance-based ADL ability; both were very sensitive tools and they are therefore recommended for use in future studies within people with COPD. It is important to note that people with COPD may demonstrate problems in both ADL motor and process ability, even though they may still be able to perform ADL tasks independently. As the AMPS, unlike many other ADL assessments, does not consider independence as the only criterion for competent task performance, but also effort, efficiency, and safety, ${ }^{11}$ it can be used in people with COPD much earlier in the disease trajectory owing to its sensitivity in detecting observable problems in ADL performance. By using the AMPS, strategic intervention planning can begin even before independence in ADL is threatened. Finally, the present study indicates that health professionals need to be aware of the need for both assessing and supporting persons with COPD in everyday technology use and ADL in order to maintain or improve their QOL.

\section{Conclusions}

Use of everyday technology and quality of ADL performance seem to be associated with HRQOL in individuals living with COPD. Surprisingly, the only demographic variable that associated with HRQOL was years with COPD. These findings indicate that health professionals should enhance their attention also to ADL-performance and everyday technology use in pulmonary rehabilitation to improve QOL for people with this devastating disease.

Given these findings, future research should further explore more in detail how people living with COPD experience their ADL performance and everyday technology use in their daily management of the disease, as it may have an impact on their perceived QOL.

\section{Literature Search}

A structured literature search was conducted in PubMed and Cinahl. Topics of COPD, ADL, everyday technology and HRQOL were included and combined with Medical Subject Headings (MeSH) or Cinahl headings.

\section{Ethical Approval and Informed Consent}

The study complied, in all aspects, with the formal requirements for research on humans in Denmark ${ }^{69}$ and with the Declaration of Helsinki. ${ }^{70}$ Individual appointments were made if participants gave verbal consent by telephone to participate in the study. Written consent was obtained from the participants immediately before data collection, where they were informed that they could withdraw from the study at any time without any consequences. Moreover, participants were informed that data would be anonymized and treated confidentially. The study was approved according to the Danish Data Protection Agency (FOU-UU-2018-003). Further ethical approval was not required for this kind of research in Denmark.

\section{Acknowledgments}

The authors would like to thank participants who took part in this study. The authors also thank from the University College of Northern Denmark, Division of Occupational Therapy a group of students and the following colleagues: Jette Andersen, Marie Bang, Tanja L. Jensen, and Sanne Heidemann-Lehmann.

\section{Funding}

This study was supported financially by The Danish Association of Occupational Therapists Association, Technologies Closely Connected to Citizens' Health and Division of Occupational Therapy, University College of Northern Denmark.

\section{Disclosure}

Mrs Rina Juel Kaptain reports grants from The Danish foundation of Occupational Therapy, during the conduct of the study. The authors report no other conflicts of interest in this work.

\section{References}

1. Centers for Disease Control and Prevention. Measuring Healthy Days. Atlanta, Georgia: CDC;2000.

2. Spruit MA, Singh SJ, Garvey C, et al. An official American thoracic society/European respiratory society statement: key concepts and advances in pulmonary rehabilitation. Am J Respir Crit Care Med. 2013. doi:10.1164/rccm.201309-1634ST

3. Paddison JS, Cafarella P, Frith P. Use of an Australian quality of life tool in patients with COPD. COPD J Chronic Obstr Pulm Dis. 2012;9 (6):589-595. 
4. Bendixen HJ, Wæhrens EE, Wilcke JT, Sørensen LV. Self-reported quality of ADL task performance among patients with COPD exacerbations. Scand J Occup Ther. 2014;21(4):313-320. doi:10.3109/ 11038128.2014 .899621

5. Gustafsson S, Eklund K, Wilhelmson K, et al. Long-term outcome for ADL following the health-promoting RCT-elderly persons in the risk zone. Gerontologist. 2013;54(4):654-663. doi:10.1093/geront/gns121

6. Lomborg K, Bjørn A, Dahl R, Kirkevold M. Body care experienced by people hospitalized with severe respiratory disease. $J$ Adv Nurs. 2005;50(3):262-271. doi:10.1111/jan.2005.50.issue-3

7. Annegarn J, Meijer K, Passos VL, et al. Problematic activities of daily life are weakly associated with clinical characteristics in COPD. $\mathrm{J} \mathrm{Am}$ Med Dir Assoc. 2012;13(3):284-290. doi:10.1016/j.jamda.2011.01.002

8. Bourbeau J. Activities of life: the copd patient. COPD J Chronic Obstr Pulm Dis. 2009;6(3):192-200. doi:10.1080/15412550902902638

9. Kaplan RM, Ries AL. Quality of life: concept and definition. COPD $J$ Chronic Obstr Pulm Dis. 2007;4(3):263-271. doi:10.1080/ 15412550701480356

10. Occupational therapy practice framework: Domain and process (3rd ed.). FRAMEWORK: domain \& process. Am J Occup Ther. 2014;68 (Suppl 1):S1-S51. doi:10.5014/ajot.2014.682006

11. Fisher AG, Jones KB. Assessment of Motor and Process Skills. Volume 1: Development, Standardization, and Administration Manual. 7th ed. Fort Collins: Three Star Press, Inc.; 2010.

12. Von Bülow C Development and Evaluation of an Adaptational Program [dissertation]. Odense: University of Southern Denmark; 2015.

13. Hu J, Meek P. Health-related quality of life in individuals with chronic obstructive pulmonary disease. Hear Lung. 2005;34 (6):415-422. doi:10.1016/j.hrtlng.2005.03.008

14. Theander K, Jakobsson P, Jörgensen N, Unosson M. Effects of pulmonary rehabilitation on fatigue, functional status and health perceptions in patients with chronic obstructive pulmonary disease: a randomized controlled trial. Clin Rehabil. 2009;23:125-136 doi:10.1177/0269215508096174

15. Kim HFS, Kunik ME, Molinari VA, et al. Functional impairment in COPD patients: the impact of anxiety and depression. Psychosomatics. 2000;41(6):465-471. doi:10.1176/appi.psy.41.6.465

16. Lindenmeyer A, Greenfield SM, Greenfield C, Jolly K. How do people with COPD value different activities? An adapted meta-ethnography of qualitative research. Qual Health Res. 2017;27 (1):37-50. doi:10.1177/1049732316644430

17. Paes T, Machado FVC, Cavalheri V, Pitta F, Hernandes NA. Multitask protocols to evaluate activities of daily living performance in people with COPD: a systematic review. Expert Rev Respir Med. 2017;11(7):581-590. doi:10.1080/17476348.2017.1335198

18. Walke LM, Mcgloin J, Towlw V, Tinette ME. Symptom management in older adults with COPD. J Am Geriatr Soc. 2006;54(4):93.

19. Tkáć J, Man SFP, Sin DD. Review: systemic consequences of COPD. Ther Adv Respir Dis. 2007;1(1):47-59. doi:10.1177/1753465807082374

20. Willgoss T, Yohannes A, Goldbart J, COPD FF. and anxiety: its impact on patients' lives. Nurs Times. 2011;107(15-16):16-19.

21. Maekura R, Hiraga T, Miki K, et al. Personalized pulmonary rehabilitation and occupational therapy based on cardiopulmonary exercise testing for patients with advanced chronic obstructive pulmonary disease. Int $J$ Chronic Obstr Pulm Dis. 2015;10:1787-1800. doi: $10.2147 / \mathrm{COPD}$

22. Martinsen U, Bentzen H, Holter MK, et al. The effect of occupational therapy in patients with chronic obstructive pulmonary disease: A randomized controlled trial. Scand J Occup Ther. 2016;8128: (May):1-9.

23. Morgan DD, White KM. Occupational therapy interventions for breathlessness at the end of life. Curr Opin Support Palliat Care. 2012;6(2):138-143. doi:10.1097/SPC.0b013e3283537d0e

24. Emiliani PL. Assistive Technology (AT) versus Mainstream Technology (MST): the research perspective. Technol Disabil. 2006;18(1):19. doi:10.3233/TAD-2006-18104
25. Hagberg JE. 2008. Livet Genom Tekniklandskabet. Livslopp, Aldrende Och Vardagsteknikens Förändring. [Life Through the Technical Landscape. The Course of Life, Aging, and Everyday Technology's Change]. Linköping: Linköpings Universitet. Swedish.

26. Nygård L, Starkhammar S. The use of everyday technology by people with dementia living alone: mapping out the difficulties. Aging Ment Health. 2007;11(2):144-155. doi:10.1080/13607860600844168

27. Ryd C, Nygård L, Malinowsky C, Öhman A, Kottorp A. Can the everyday technology use questionnaire predict overall functional level among older adults with mild cognitive impairment or mildstage alzheimer's disease? - a pilot study. Scand J Caring Sci. 2017;31:1-9.

28. Williams V, Bruton A, Ellis-Hill C, McPherson K. What really matters to patients living with chronic obstructive pulmonary disease? An exploratory study. Chron Respir Dis. 2007;4(2):77-85. doi:10.1177/1479972307078482

29. Udsen FW, Lilholt PH, Hejlesen O, Ehlers L. Effectiveness and cost-effectiveness of telehealthcare for chronic obstructive pulmonary disease: study protocol for a cluster randomized controlled trial. Trials. 2014;15:178. doi:10.1186/1745-6215-15-178

30. Nield M, Hoo GWS. Real-time telehealth for COPD self-management using skype ${ }^{\mathrm{TM}}$. COPD J Chronic Obstr Pulm Dis. 2012;9(6):611-619. doi:10.3109/15412555.2012.708067

31. Schou L, Østergaard B, Rasmussen LS, Rydahl-Hansen S, Phanareth K. Cognitive dysfunction in patients with chronic obstructive pulmonary disease - A systematic review. Respir Med. 2012;106 (8):1071-1081. doi:10.1016/j.rmed.2012.03.013

32. Pereira EDB, Viana CS, Taunay TCE, Sales PU, Lima JWO, Holanda MA. Improvement of cognitive function after a three-month pulmonary rehabilitation program for COPD patients. Lung. 2011;189:279-285. doi:10.1007/s00408-011-9303-6

33. Global initiative for Chronic Obstructive Lung Disease (GOLD) [homepage on the Internet]. Fontana: global strategy for the diagnosis, management and prevention of COPD. 2017. Avaiable from: https://goldcopd.org/gold-2017-global-strategy-diagnosismanagement-prevention-copd/. Accessed February 12, 2017..

34. Brandl M, Böhmer M, Brandstetter S, et al. Factors associated with generic health-related quality of life (HRQOL) in patients with chronic obstructive pulmonary disease (COPD): a cross-sectional study. $J$ Thorax Dis. 2018;10(2):766-775. doi:10.21037/jtd.2018.01.122

35. DePoy E, Gitlin LN. Introduction to Research: Understanding and Applying Multiple Strategies. 4th ed. St. Louis: Elsevier; 2011:369 p.

36. McHorney CA, Ware JE, Raczed AE, The MOS. 36-item short-form health survey (SF-36): III.Psychometric and clinical tests of validity in measuring physical and mental health constructs. Med Care. 1993;31(3):247-263. doi:10.1097/00005650-199303000-00006

37. Bjørner JB, Damsgaard T, Watt T, et al. Dansk Manual Til SF-36. Et Spørgeskema Om Helbredsstatus. [Danish Manual for SF-36. A Questionnaire About Health Status]. Copenhagen: Lægemiddelindustriforeningen; 1997.

38. Nygård L, Rosenberg L, Kottorp A. User Manual: Everyday Technology Use Questionnaire (ETUQ) Everyday Technology in Activities at Home and in Society. Stockholm, Sweden: Karolinska Institutet, Division of Occupational Therapy; 2016.

39. Kaptain RJ, Kottorp A, Patomella AH, Helle T. Inter-rater and test-retest reliability of the Danish version of the everyday technology use questionnaire. Scand J Occup Ther. 2017;26(3):226-234. doi:10.1080/11038128.2017.1395910

40. Rosenberg L, Nygård L, Kottorp A. Everyday technology use questionnaire: psychometric evaluation of a new assessment of competence in technology use. OTJR Occup Particip Heal. 2008;29 (2):52-62. doi:10.3928/15394492-20090301-05

41. Rosenberg L, Kottorp A, Winblad B, Nygård L. Perceived difficulty in everyday technology use among older adults with or without cognitive deficits. Scand J Occup Ther. 2009;16(4):216-226. doi:10.3109/11038120802684299 
42. Nygård L, Pantzar M, Uppgard B, Kottorp A. Detection of activity limitations in older adults with MCI or Alzheimer's disease through evaluation of perceived difficulty in use of everyday technology: a replication study. Aging Ment Health. 2012;16(3):361-371. doi:10.1080/13607863.2011.605055

43. Miller MR, Hankinson J, Brusasco V, et al. ATS/ERS Task Force. Standardisation of spirometry. Eur Respir J. 2005;26:319-338. doi:10.1183/09031936.05.00034805

44. Bond TG, Fox CM. Applying the Rasch Model: Fundamental Measurement in the Human Sciences. 2nd ed. Journal of Educational Measurement. 2007;360.

45. Wæhrens EE Measuring Quality of Occupational Performance Based on Self-report and Observation: Development and Validation of Instruments to Evaluate ADL Task Performance [dissertation]. Umeå: Umeå University; 2010.

46. Hedman A, Nygård L, Almkvist O, Kottorp A. Patterns of functioning in older adults with mild cognitive impairment: a two-year study focusing on everyday technology use. Aging Ment Health Informa Healthcare. 2013;17(6):679-688. doi:10.1080/13607863.20 13.777396

47. Wæhrens EE, Bliddal H, Danneskiold-Samsøe B, Lund H, Fisher AG. Differences between questionnaire- and interview-based measures of activities of daily living (ADL) ability and their association with observed ADL ability in women with rheumatoid arthritis, knee osteoarthritis, and fibromyalgia. Scand J Rheumatol. 2012;41 (2):95-102. doi:10.3109/03009742.2011.632380

48. Field A. Discovering Statistics Using IBM SPSS Statistics. 4th ed. Los Angeles, London, New Delhi, Singapore, Washington DC: Sage Publications; 2014:916.

49. Theme Horse. Statistics How To. WordPress; 2018.

50. Barken TL, Thygesen E, Söderhamn U. Unlocking the limitations: living with chronic obstructive pulmonary disease and receiving care through telemedicine - A phenomenological study. J Clin Nurs. 2018;27:132-142. doi:10.1111/jocn.2018.27.issue-1pt2

51. Zwerink M, Brusse-Keizer M, van der Valk PD, et al. Self management for patients with chronic obstructive pulmonary disease. Cochrane Database Syst Rev. 2014;5(3):CD002990.

52. Danish Health Authority [homepage on the Internet]. Copenhagen: telemedicinsk understøttelse af behandlingstilbud til mennesker med KOL - anbefalinger for målgruppe, sundhedsfagligt indhold samt ansvar og samarbejde [Telemedicin support of treatment options for people with COPD - recommendations for target group, health professional content and responsibility and collaboration]; 2017. Available from: https://www.sst.dk/da/udgivelser/2017/telemedi cinsk-understoettelse-af-behandlingstilbud-til-mennesker-med-kol. Accessed April 12, 2019. Danish.

53. Early F, Young JS, Robinshaw E, Mi Emma Z, Mi Ella Z. A case series of an off-the-shelf online health resource with integrated nurse coaching to support self-management in COPD. Int J Chronic Obstr Pulm Dis. 2017;12:2955-2967. doi:10.2147/COPD.S139532

54. Bentsen SB, Rokne B, Klopstad W. Comparison of health-related quality of life between patients with chronic obstructive pulmonary disease and the general population. Scand $J$ Caring Sci. 2013;27:905-912. doi:10.1111/scs.12002
55. Reardon JZ, Lareau SC, ZuWallack R. Functional status and quality of life in chronic obstructive pulmonary disease. Am J Med. 2006;119 (Suppl A10):S32-S37. doi:10.1016/j.amjmed.2006.08.005

56. Schaefer K. Commentary: patients with end-stage COPD did not ask for help because they felt normal and did not realise the situation could be improved. Evid Based Nurs. 2009;12(3):95. doi:10.1136/ebn.12.3.95

57. Habraken JM, Pols J, Bindels PJE, Willems DL. The silence of patients with end-stage COPD: a qualitative study. $\mathrm{Br} J$ Gen Pract. 2008;58:844-849. doi:10.3399/bjgp08X376186

58. Van Deursen AJ, van Dijk JA, Peters O. Rethinking Internet skills: the contribution of gender, age, education, internet experience, and hours online to medium-and content-related internet skills. Poetics. 2011;39(2):125-144. doi:10.1016/j.poetic.2011.02.001

59. Fang ML, Canham SL, Battersby MA, et al. Exploring privilege in the digital divide: implications for theory, policy, and practice. Gerontologist. 2019;59(1):e1-e15. doi:10.1093/geront/gny037

60. Chopik WJ. The benefits of social technology use among older adults are mediated by reduced loneliness. Cyberphychol Behav Soc Netw. 2016;19(9):551-556. doi:10.1089/cyber.2016.0151

61. Golant S. Aging in the Right Place. Towson: Health Professions Press; 2015.

62. Divo M. COPD, Co-morbidities and health-related quality of life (HRQOL): more is less. COPD J Chronic Obstr Pulm Dis. 2013;10:275-276. doi:10.3109/15412555.2013.795409

63. Van Manen J. The influence of COPD on health-related quality of life independent of the influence of comorbidity. $J$ Clin Epidemiol. 2003;56:1177-1184. doi:10.1016/S0895-4356(03)00208-7

64. Lins L, Carvalho FM. SF-36 total score as a single measure of health-related quality of life: scoping review. SAGE Open Med. 2016;4:1-12. doi:10.1177/2050312116671725

65. Moll L, Lange P, Dahl BH. 2011. KOL Sygdom, Behandling Og Organisation. [COPD Illness, Treatment and Organization]. Munksgaard, Danmark: Copenhagen. Danish.

66. Bustamante V, Lópes de Santa María E, Gorostiza A, Jiménez U, Gáldiz JB. Muscle training with repetitive magnetic stimulation of the quadriceps in severe COPD patients. Respir Med. 2012;104 (2):237-245. doi:10.1016/j.rmed.2009.10.001

67. Moy ML, Reilly JJ, Ries AL, et al. Multivariate models of determinants of health-related quality of life in severe chronic obstructive pulmonary disease. J Rehabil Res Dev. 2009;46(5):643-654. doi:10.1682/JRRD.2008.09.0127

68. Frith P, Crockett A, Beilby J, et al. Simplified COPD screening: validation of the PiKo- $6^{\mathbb{R}}$ in primary care. Prim Care Respir J. 2011;20:190-198. doi:10.4104/pcrj.2011.00040

69. Regulation (EU) 2016/679 of the European Parliament and of the Council of 27 April 2016 on the protection of natural persons with regard to the processing of personal data and on the free movement of such data, and repealing Directive 95/46/EC (General Data Protection Regulation). Official Journal of the European Union. Available from: https://eur-lex.europa.eu/legal-content/EN/TXT/PDF/?uri= CELEX:32016R0679\&from=EN. Accessed May 7, 2019.

70. Krleza-Jeric K, Lemmens T. 7th revision of the declaration of Helsinki: good news for the transparency of clinical trials. Croat Med J. 2009;50:105-110. doi:10.3325/cmj.2009.50.105

International Journal of Chronic Obstructive Pulmonary Disease

\section{Dovepress}

\section{Publish your work in this journal}

The International Journal of COPD is an international, peer-reviewed journal of therapeutics and pharmacology focusing on concise rapid reporting of clinical studies and reviews in COPD. Special focus is given to the pathophysiological processes underlying the disease, intervention programs, patient focused education, and self management protocols. This journal is indexed on PubMed Central, MedLine and CAS. The manuscript management system is completely online and includes a very quick and fair peer-review system, which is all easy to use. Visit http://www.dovepress.com/testimonials.php to read real quotes from published authors. 